\title{
SIR EDMUND WHITTAKER, F.R.S.
}

\section{by D. MARTIN}

Edmund Taylor WhitTaker was born at Birkdale, Lancashire, on 24th October 1873 and belonged to a family which had been known for several generations in the district where the Ribble forms the boundary between Lancashire and Yorkshire. He entered Manchester Grammar School in $\mathbf{1 8 8 5}$ and spent two years in the Classical side before turning over to the Mathematical side. In December 1891 he won a scholarship to Trinity College, Cambridge, and, after an undergraduate career of unusual distinction, was bracketed with J. H. Grace as Second Wrangler in the Tripos of 1895 ; Bromwich was Senior Wrangler. In 1896 Whittaker was elected a Fellow of Trinity College and in 1897 was first Smith's prizeman, his essay being entitled "On the reduction of the theory of multiform functions to uniform functions."

Whittaker's working life from now onwards can be divided into three parts, namely, his Cambridge days from his election to his fellowship until 1906 when he became Astronomer Royal for Ireland, his time in Dublin until 1912 when he was appointed Professor of Mathematics in the University of Edinburgh, and the rest of his life spent in Edinburgh.

During his period in Cambridge, Whittaker wrote two of the five standard treatises which have made a major contribution to his fame and for which he will long be remembered. The first of these, $A$ course of modern analysis : an introduction to the general theory of infinite series and of analytic functions; with an account of the principal transcendental functions, appeared in 1902 and grew out of a new Tripos course which its author had given. In order to appreciate the significance of the appearance of this book, it is essential to realise that at the end of last century the general theory of functions as developed by Cauchy, Weierstrass and other Continental mathematicians was hardly known in this country. The important treatise by Forsyth had certainly appeared in 1893, but its contents had not penetrated to the rank and file of mathematicians. Indeed, Whittaker often used to relate how at the time he sat the Tripos examination, Cambridge mathematicians were speaking of "Cocky's" theorem! Modern Analysis was therefore the first book in English to present the theory of functions of a complex variable at undergraduate level. Despite the general excellence of the work, it contained some inadequacies (for example, in the treatment of Cauchy's theorem); moreover, a few years after its publication, Hardy's Pure Mathematics and Bromwich's Infinite Series appeared. Consequently, when a second edition was called for, the first few chapters were considerably altered; and, at the same time, the book was enlarged by about 200 pages through the addition of some further chapters. For this major overhaul, Whittaker had the aid of his former pupil G. N. Watson, whose name was added to the title-page of the new edition (1915). The second part of the book, dealing with the higher transcendental functions, is still the most comprehensive work on the subject. It became

$$
\text { E.M.S.-A }
$$


particularly useful when wave mechanics was being developed in the years 1925 and 1926 and solutions of Schrödinger's equation were being ardently sought after. The treatment is very general, the special functions being defined by contour integrals rather than by differential equations. To the analyst, it gives a comprehensive outlook on these functions, whose properties are established by the general analysis which it is the primary aim of the first part of the book to expound. Apart from the insertion of a chapter on Ellipsoidal Harmonics, the third and fourth editions differ from the second in only minor ways; however, at present, the whole book is being revised and brought up to date by Professor Watson.

The second treatise written by Whittaker while in Cambridge was $A$ treatise on the analytical dynamics of particles and rigid bodies, with an introduction to the problem of three bodies; it was published in 1904. This was the first systematic account to be given in English of general dynamical theory, i.e. the superbly beautiful theory which springs from Hamilton's equations and which has turned out to be of such fundamental importance for the development of quantum mechanics. It was in the chapter on transformation theory that Whittaker made the oft-quoted assertion that "the whole course of a dynamical system can thus be regarded as the gradual self-unfolding of a contact-transformation". The book also contains a discussion of the Problem of three bodies on which Whittaker had already written a report for the British Association in 1899. The compilation of this report must have been most laborious for, between 1750 and 1905, more than 800 memoirs were published on the subject.

Concerning the original work done by Whittaker during his years in Cambridge, mention should first be made of his long paper on automorphic functions, published in 1898. Whittaker maintained an intense interest in automorphic functions throughout the whole of his life, and an account of his work on them is given in the paper (pp. 25-30) by R. A. Rankin. Then in 1902 and 1903 he published two papers on the partial differential equations of mathematical physics in which he obtained the solution of Laplace's equation with which his name is associated. An account of this work and of related work done years later in Edinburgh is given by G. Temple in the Whittaker Memorial Lecture, printed on pp. 11-24.

Whittaker had always maintained an interest in Astronomy (he had won the Sheepshanks Exhibition in Astronomy in 1894) and during the early years of the century wrote several papers on Dynamical Astronomy. It is therefore not altogether surprising that in 1906 he accepted the post of Astronomer Royal for Ireland and Andrews Professor of Astronomy in the University of Dublin. During his stay in Cambridge, he had made his mark on the Tripos courses and no doubt his many distinguished pupils, including H. Bateman, A. S. Eddington, G. H. Hardy, J. H. Jeans, J. E. Littlewood, G. I. Taylor, H. W. Turnbull and G. N. Watson, owed much to his inspiring teaching and to his outlook on mathematics, both pure and applied. 
The second period of Whittaker's academic life, namely, his six years in Dublin, is characterised by the comparative leisure which he was afforded and which enabled him to write the original version of the book which has turned out to be his magnum opus-A history of the theories of aether and electricity, from the age of Descartes to the close of the 19 th century-and which was published in 1910. This volume was to a considerable extent rewritten and made the first volume of a new work with practically the same title, after Whittaker retired from his Edinburgh chair in 1946. We shall refer to this again later.

There also appeared in 1907 the Cambridge Tract entitled The theory of optical instruments. The book is written in Whittaker's characteristic style and of special interest is the account given of Klein's application of the imaginary circle at infinity to prove the result that no optical instrument, other than a plane mirror, can possibly be constructed to transform all the points of the object space into the image space.

Among Whittaker's pupils in Dublin was Eamon de Valera, who later became Prime Minister of Eire. Mr de Valera consulted Whittaker from time to time in later years and in particular sought his advice about the founding of the Dublin Institute for Advanced Studies.

In 1912 Whittaker moved to Edinburgh to fill the chair of Mathematics in succession to George Chrystal, and for the next 34 years rendered to the University unswerving loyalty and service, all the time adding lustre to his chair by his outstanding personality and by the achievements of himself and his colleagues.

As soon as he settled in Edinburgh, Whittaker began to inject fresh vitality into his department. Within a year or so of his arrival, he had instituted the mathematical laboratory, he had started to give " research lectures " and our Society had held its first colloquium.

The advertisement intimating the opening of the laboratory in October 1913 specified the subjects to be taught (some of which were interpolation, method of least squares, solution of systems of linear equations, evaluation of determinants, determination of roots of transcendental equations, practical Fourier analysis, evaluation of definite integrals, numerical solution of differential equations, construction of tables of functions not previously tabulated such as parabolic cylinder functions) and also indicated that facilities were available for original research and that the University would grant recognition, under certain conditions, to research students who would be permitted to offer themselves for the degree of D.Sc. The content of the syllabus may seem quite commonplace nowadays, but it was not so in 1913 ; these matters had not previously been systematically taught in any British university. That the laboratory was likely to supply a very definite need was indicated by the fact that several requests were received for a vacation 'course in the summer of 1913 from persons unable to attend during the normal academic teaching terms. This demand led to the running of the first mathematical colloquium 
by our Society. The colloquium was held for five days in August 1913 and was attended by about eighty people. Although its primary object was to provide instruction in some aspects of numerical mathematics, Whittaker took the view that its scope should be widened by the inclusion of other fields of mathematical thought. Consequently, lectures were given by D. M. Y. Somerville on Non-euclidean geometry and the foundations of geometry and by A. W. Conway on The theory of relativity and the new physical ideas of space and time. The numerical work, which was carried out by the 80 members under Whittaker's supervision, consisted in a study of the light curves of two variable stars, a harmonic analysis being made of one and a periodgram analysis of the other. Thus began the series of colloquia which have been held from time to time by our Society-they are now held in St Andrews-and whose object is still the provision of short courses of a survey nature on growing branches of Mathematics.

The fifth of the standard works by Whittaker and in this case prepared with the aid of his colleague G. Robinson, is entitled The calculus of observations; a treatise on numerical mathematics and grew out of his lectures in the mathematical laboratory. When it was published (in 1924) very little of the material contained in its 400 pages was to be found in any other textbook in English.

Besides teaching numerical mathematics to undergraduates, Whittaker wrote several papers on the subject and on graduation theory in particular. These, along with some papers on algebraic topics, are discussed by A. C. Aitken in his paper on pp. 31-38.

The second innovation made by Whittaker on coming to Edinburgh was the institution of the " research lectures" for staff, post-graduate students and visitors. These were given twice weekly, usually at three o'clock in the afternoon, and their principal aim was to bring into prominence topics suitable for original investigation. Their subject matter was related either to Whittaker's own researches at the time or to some important matter of contemporary interest. For instance, when Einstein first produced a unified field theory the lectures dealt with that theory while a course on spinors followed the publication by Cartan of his important book on the subject. Whittaker's ability to absorb and digest so much fresh mathematical work and to lecture on it term after term was truly remarkable. For it must be emphasized that his lecture notes were not just verbatim copies of the essential parts of the published papers on the subject, but contained what was almost a redevelopment of the subject by himself. His notes, incidentally, were written out in great detail and he wrote on the blackboard practically everything that he said. He wrote extremely fast but his writing was always legible. At the end of a lecture he may have been physically tired but he was certainly mentally exhilarated. The research room in the Mathematical Institute is a small homely lecture room with a fire-place at the back, and a fow minutes before the end of Whittaker's lecture someone in the back row would put the kettle 
on the fire so that by four o'clock tea would be ready. Whittaker would then relax in his armchair by the fire, serenely happy with his colleagues and visitors around him, while the animated discussion which arose would cover anything from the lecture just given to academic affairs or religion. In this atmosphere Whittaker was in a most exhilarating form and the inspiration seemed to flow from him. Indeed, as far as research work is concerned, it is rather for his power of inspiring others than for his own work that he will long be remem. bered. It is interesting to note that by 1915,11 original papers had emanated from his department. These were mainly on Lamé and Mathieu functions and were the work of E. L. Ince, L. R. Ford, A. Milne, E. Blades, A. G. Burgess and Whittaker himself; they were issued separately with blue covers and bearing the name of the Department on the outside. Another indication of the vitality of the Department is the fact that between the years 1912 and 1946 no fewer than 18 theses on subjects in pure mathematics were accepted for the degree of D.Sc. and 13 for the degree of Ph.D.

Whittaker's own work on Lamé and Mathieu functions is referred to by G. Temple in the paper already mentioned. Later on, he became intensely interested in the Theory of Relativity and wrote a number of papers on some of its mathematical aspects ; these are discussed by J. I. Synge in a paper on pp. 39-55. His interest in Relativity manifested itself also at the undergraduate level, for the Honours course entitled Higher Algebra and Geometry contained neither Algebra nor Geometry in the ordinary sense of these terms but comprised Tensor Calculus with Riemannian Geometry and its generalisations. It was Whittaker, incidentally, who suggested to Levi-Civita that his book Lezioni di calcolo differenziale assoluto should be translated into English.

With regard to staff, Whittaker adopted the policy of appointing brilliant young mathematicians from other universities, of encouraging them in and helping them with their researches, and then, after they had given a few years' service, of sending them away to more senior posts, often professorships, elsewhere. Among those of Whittaker's staff who obtained chairs are A. C. Aitken, who succeeded him in his Edinburgh chair, B. Baker, E. T. Copson, L. R. Ford, W. H. McCrea, H. S. Ruse and J. M. Whittaker. A. G. Walker, although never actually on the staff, is another distinguished product of the Edinburgh school who now occupies a chair.

It must not be inferred from what has been said about the effort which Whittaker expended on advanced study and research that he had little interest in the undergraduate teaching in his department. Far from it; he gave one course each year to the Honours classes, he often took the Second Ordinary Class (i.e. the class containing the best of the first year students) sometime during the session and he always lectured to the First Ordinary Class once a week on the history and development of mathematics. This last duty was in keeping with the tradition in the Scottish universities whereby a professor always lectured to his Ordinary class; as has been said "it would never do for a student to go out without having seen an Arts professor" !

E.M.S.-A 2 
As far as Whittaker's weekly lectures to the First Ordinary Class are concerned, it is doubtful if the majority of the students gathered much real knowledge from them, because a proper appreciation of the work would have required a greater degree of maturity than the students were likely to have possessed. In order to illustrate the kind of work done in this very unique course, a few degree examination questions are quoted here :

(1) Describe the discoveries of the Pythagoreans in Cosmology.

(2) Explain the difference between projective and elliptic geometry. Prove that in three dimensions four skew lines have in general two common transversals. Deduce that in elliptic space two skew lines have in general two common perpendiculars, and describe what happens when there are more than two. .

(3) Define cardinal number, and distinguish finite from transfinite numbers.

(4) Discuss the relation of mathematical laws to physical investigation.

However, and this is most important, the students were made to realise that mathematics is a living subject and is not as completely worked out as they had probably imagined at one time. Furthermore, Whittaker was an outstanding lecturer and by his dignified bearing, his great command of language, his eloquent delivery and his obvious mastery of his subject, he made a tremendous impact upon young students straight from school. They knew at once that they were in the presence of a scholar and teacher of the first rank and in all his prelections they saw at work a mind of astonishing accuracy and force, ranging at will over the whole field of ancient and modern mathematics and presenting to them with insight and great persuasive power the profundities there disclosed. Whittaker's lectures to the Second Ordinary Class were equally persuasive, and any Science student who came to the University with doubts as to which subject in which to specialise very quickly had them dispelled.

Whittaker was very generous in his appreciation of the talents of his friends and pupils and took a deep personal interest in his Honours students whom he kept track of in after years. I once asked him if he could write for the Edinburgh Mathematical Notes a short obituary notice of a schoolmaster who had been an Edinburgh graduate and received a notice of a page or so in length by return of post. The note mentioned things which could not have been easily obtained from official records and which must therefore have come either from his memory or from a private record. Whittaker, it may be added here, was extremely punctilious in all his doings and dealt with correspondence with the minimum of delay. He never had a secretary-he would have regarded one as a hindrance rather than a help-and never used a typewriter. His characteristic handwriting, although written at great speed, was always perfectly legible.

Whittaker retired from his chair in 1946 , not to rest but to continue working 
with unabated vigour. In 1951 a revised version of his book The history of the theories of aether and electricity was published. This appeared as the first volume of a new treatise with the same title and it deals with the development of mathematical physics up to the end of the nineteenth century. The second volume, which appeared in 1953, contains an account of the developments which took place between 1900 and 1926 and is mainly concerned with Relativity and the Quantum Theory. The two volumes, taken together, form Whittaker's magnum opus. The amount of preparatory reading required for the writing of them must have been stupendous and I doubt if there existed any other person with the necessary background of knowledge to have written them. The books give a connected account of the development of the funda. mental theories of physics and contain the distilled essence of their author's reading and study over a period of more than half a century. Whittaker had in mind a third volume, dealing with developments made since 1926 , but this was never completed. I think he would have had great difficulty in shaping it into final form, for some of the recent theories are in anything but a finished state and the " bad" mathematics so successfully used in quantum field theory was revolting to him.

During his years of retirement Whittaker devoted much of his time to the philosophical aspects of modern physics, and his ideas are expounded in his Tarner Lectures, Donnellan Lectures and in other writings. An assessment of these is given (pp. 57-68) by the Rev. James McConnell. There is no doubt that the new physics has a considerable bearing on theology, but this has so far been appreciated by relatively few people, since few scholars are sufficiently competent both as mathematicians and as theologians. Whittaker held an almost unrivalled position in this respect, for he had been a deeply religious man all his life and had read widely in Christian theology. After having belonged to several denominations of the Protestant Church, including the Church of Scotland, of which he was an elder, he was received into the Church of Rome in 1930.

Whittaker's religion permeated his whole life, including his mathematics. Although he would admire an elegant piece of work in pure mathematics and could, as J. L. Synge says below, make the symbols dance to his own tune, he nevertheless regarded mathematics as a tool for finding out more about the universe and the fundamental laws which regulate the course of phenomena in it. For example, he found great satisfaction in knowing that the wholc of electrostatics can be derived from a single postulate, but he probably had little interest in solving particular problems in electrostatics, unless the actual mathematics happened to be interesting. One may say that he was a natural philosopher though not a physicist.

In the light of what has just been said, it is not surprising that Whittaker had an intense interest in the work carried out by A. S. Eddington during the last sixteen years of his life, and he edited and chose the title of Eddington's last book Fundamental Theory, which was published posthumously in 1946. 
Although Whittaker did not agree with all that Eddington wrote and said, he had great admiration for his efforts to relate the theories of macroscopic and microscopic physics, as indeed would anyone who considers that it is a fundamental aim of philosophy to give a synoptic view of the universe and bring apparently diverse phenomena into intelligible relation.

From the time he came to Edinburgh, Whittaker maintained a genuine and sustained interest in the affairs of our Society, of which he was an Honorary Member. He was a regular attender at the ordinary meetings and at the colloquia and gave excellent lectures from time to time. Because of his extraordinary versatility he could always be relied upon to make an interesting contribution to the discussion after any lecture. Moreover he was a marvellous raconteur, and, with a great fund of academic anecdotes at his disposal, could enliven the proceedings in a very acceptable manner. One of the few subjects on which I have never heard him discourse is Geometry in the Bakerian sense ; Geometry for him meant Riemannian geometry which is used in Relativity and contributes to our understanding of the material universe.

Whittaker served on the Council of the London Mathematical Society from 1899 until 1905, was President for the session 1928-29 and was awarded the de Morgan Medal of the society in 1935 . He was also President of the Mathematical Association during the session 1920-21.

Whittaker also rendered devoted service to the Royal Society of Edinburgh, of which he was President from 1939 until 1944. He made an admirable president and carried out his duties with much dignity and grace. The addresses which he gave to the society during this period on general topics such as Spin in the universe and Some disputed questions in the philosophy of the physical sciences are well worth studying. At the conclusion of his presidency a bronze bust of him was executed by Benno Schotz, R.S.A. and placed in the Society's House in George Street.

The Royal Society (of London), of which Whittaker was made a Fellow in 1905, also claimed a share of his time and interest. He served on the Council during the session 1911-12 and from 1933 until 1935. He was awarded the Sylvester Medal in 1931 and the Copley Medal in 1954.

He was also President of Section A of the British Association in 1927 and his presidential address on The outstanding problems of relativity dealt with a number of matters which are still not settled.

Numerous other honours were bestowed on Whittaker. Seven honorary degrees were conferred on him and he was made an honorary member of several learned societies. In 1935 Pope Pius XI conferred on him the cross pro Ecclesia et Pontifice and in 1936 appointed him a member of the Pontifical Academy of Sciences. In 1945 he was knighted and in 1949 was elected an Honorary Fellow of Trinity College, Cambridge.

Whittaker had few interests outside mathematics, philosophy and religion. He did, however, take a great delight in gardening and he was very fond of music, particularly that of Bach and Mozart. He did not perform on any 
instrument, but enjoyed going to concerts and listening to friends playing the piano in his home. He seemed to find music a helpful accompaniment to his thoughts, for on occasions he would do mathematics on the back of his concert programme. Whittaker was particularly happy in his home and was devoted to his family and grandchildren. In 1901 he had married Mary, daughter of the Rev. Thomas Boyd of Cambridge, and there were three sons and two daughters. The second son is J. M. Whittaker, F.R.S., Vice-Chancellor of the University of Sheffield, and the elder daughter is the wife of E. T. Copson, Regius Professor of Mathematics in the University of St Andrews. Lady Whittaker was at all times a source of strength and inspiration to her husband and was an ideal hostess at their home in George Square.

At the colloquium held at St Andrews in July 1955, Whittaker's friends saw that his strength had failed very considerably. Nevertheless, he was able to go to Cambridge in the following October to have lunch with the Queen in Trinity College, but subsequently he grew weaker and, with great tranquillity of mind and with gratitude for the good innings he had had in his earthly life, awaited his approaching end. On 24th March 1956 he passed on.

In preparing this notice, I must acknowledge help from the notices written for the Royal Society by G. Temple and for the London Mathematical Society by W. H. McCrea and also from conversations with several of Sir Edmund's friends in Edinburgh.

Department of Mathematics

THE UNIVERSITY

GLasgow, W. 2 